\title{
Temperature Dependence of Ionic Conductivity of Crosslinked Poly(propylene oxide) Films Dissolving Lithium Salts and Their Interfacial Charge Transfer Resistance in Contact with Lithium Electrodes
}

\author{
Masayoshi Watanabe, Kohei Sanui, Naoya Ogata, Fumio Inoue, ${ }^{*}$ \\ Tadahiko KoBAYASHI, ${ }^{*}$ and Zentaro OHTAKI* \\ Department of Chemistry, Sophia University, 7-1 Kioi-cho, \\ Chiyoda-ku, Tokyo 102, Japan \\ *Department of Electrical and Electronic Engineering, \\ Sophia University, 7-1 Kioi-cho, Chiyoda-ku, \\ Tokyo 102, Japan
}

(Received March 27, 1984)

\begin{abstract}
Temperature dependence of ionic conductivity of crosslinked poly(propylene oxide) (PPO) films dissolving lithium salts, $\mathrm{LiBF}_{4}, \mathrm{LiClO}_{4}$, and $\mathrm{LiSCN}$, and their interfacial charge transfer resistance in contact with lithium electrodes were determined by complex impedance method on the assumption of an equivalent circuit. It was found that the temperature dependence of the ionic conductivity and the interfacial charge transfer resistance corresponding to the electrode reactions $\left(\mathrm{Li}^{\rightleftarrows} \mathrm{Li}^{+}+\mathrm{e}\right)$ obeyed the WLF-type equation and the Arrhenius equation, respectively. The WLF parameters obtained were $C_{1} \simeq 9-15$ and $C_{2} \simeq 35-75$, and the activation energy for the electrode reactions was $0.57-1.2 \mathrm{eV}$, depending on the kinds of the incorporated salts.

KEY WORDS Ionic Conductor / Poly(propylene oxide) / Complex Impedance Method / Ionic Conductivity / Interfacial Charge Transfer Resistance / WLF-Type Equation / Arrhenius Equation /
\end{abstract}

A relatively high ionic conductivity has been recently reported in polymer complexes formed by alkali metal salts and polyethers such as poly(ethylene oxide) and poly(propylene oxide).$^{1-12}$ The discovery that the ionic conductivity reached $10^{-4}-10^{-5} \mathrm{Scm}^{-1}$ at moderate temperatures in some complexes has accelerated their research on account of their potential application as solid electrolytes to batteries. ${ }^{2,12}$ From the view point of their battery application, there are several important properties which should be evaluated in addition to the ionic conductivity. Among them the interfacial charge transfer resistance in contact with electrode materials and the transference number of ions are considered to be of great importance, because these values may often dominate the internal resistance and electromotive force of batteries. However, our knowledge about the ion conductive behavior including electrode reactions in the polyether complexes is only at a very early stage. ${ }^{12}$

In this article we investigated the ionic conductivity of the crosslinked poly(propylene oxide) (PPO) films dissolving lithium salts, $\mathrm{LiBF}_{4}, \mathrm{LiClO}_{4}$, and LiSCN, and their interfacial charge transfer resistance in contact with lithium electrodes. In order to evaluate these two different contributions to the resistance of the PPO complexes, complex impedance of a cell, lithium/PPO complex/ lithium, was measured over a wide range of frequency. The bulk resistance and the interfacial charge transfer resistance were esti- 
mated from the corresponding components of an equivalent circuit required to account for the complex impedance diagrams. Their temperature dependences were interpreted in terms of the WLF-type equation and the Arrhenius equation.

\section{EXPERIMENTAL}

\section{Samples}

Triol-type PPO (mol.wt. $=3000$ ) was obtained from Asahi Denka Co. and was dried under reduced pressure at $80^{\circ} \mathrm{C}$ for $8 \mathrm{~h}$ before use. With respect to the functional groups, stoichiometric amount of PPO and freshly distilled tolylene-2,4-diisocyanate (TDI) were mixed sufficiently and were casted on glass substrates. Crosslinking reaction occurred at $65^{\circ} \mathrm{C}$ under dry nitrogen atmosphere for $72 \mathrm{~h}$. Unreacted PPO and TDI were removed from the network films by extraction with acetone. The resulting network films obtained with thicknesses of $0.4-0.9 \mathrm{~mm}$ were dried sufficiently and were cut into disks with $13 \mathrm{~mm}$ in diameter. The disks were dipped in an acetone solution of the dried lithium salt until equilibrated and were dried under reduced pressure at $90^{\circ} \mathrm{C}$ for $72 \mathrm{~h}$. Since the potential difference over the disks could be neglected after the drying at an elevated temperature the salt might dissolve homogeneously in the network films. The concentration of the lithium salt in the disks was determined from weight change of the disks before and after the dipping and was represented by the molar ratio of the lithium salt to the repeating unit of PPO ([Salt]/[PO unit $]$ ).

\section{Methods}

The PPO complex sandwiched between lithium electrodes for electrical contacts was packed in a sealed cell with stainless steel terminals which were in contact with the measuring device. The diameter of the electrodes was the same with the PPO complex. The cell assembly was all carried out under dry argon atmosphere. Impedance measurement was employed with a Hewlett-Packard 4800A vector impedance meter equipped with a Takeda Riken TR5821 frequency counter over the frequency range of $5 \mathrm{~Hz}$ to $550 \mathrm{kHz}$. The oscilation levels were $2.7 \mathrm{mV}, 27 \mathrm{mV}, 270 \mathrm{mV}$, and $2.7 \mathrm{~V}$ depending on the sample impedance ranges of $1-10 \mathrm{k} \Omega, 10-100 \mathrm{k} \Omega, 0.1-1 \mathrm{M} \Omega$, and $1-10 \mathrm{M} \Omega$, respectively. In this range of the oscilation levels, the response of impedance was nearly linear. Temperature of samples was regulated with a Yashima Work BT-10 thermostated oven.

Differential scanning calorimetry (DSC) was measured by using a Rigaku Denki 8085 DSC apparatus at a heating rate of $20^{\circ} \mathrm{C} \mathrm{min}^{-1}$.

\section{RESULTS AND DISCUSSION}

\section{Behavior of Complex Impedance Diagrams}

We assumed here that the equivalent circuit shown in Figure 1(a) described the impedance behavior of the present cell system. Meanings of $C_{\mathrm{g}}, R_{\mathrm{b}}, R_{\mathrm{e}}$, and $C_{\mathrm{e}}$ are cited in the figure caption. On the assumption of $C_{\mathrm{g}} \ll C_{\mathrm{e}}$, which is often the case in an electrolyte cell system, the general profile of the corresponding imped-

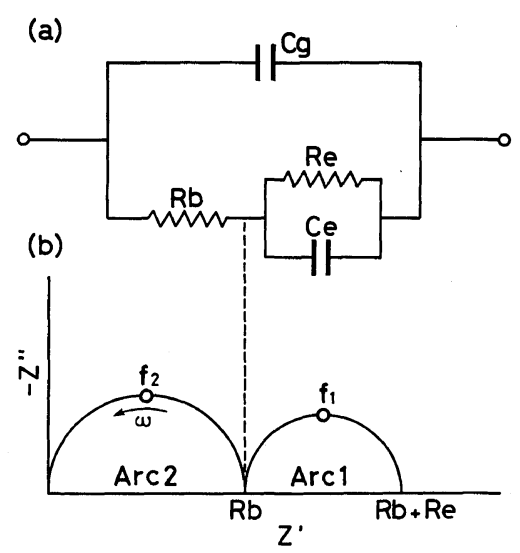

Figure 1. Equivalent circuit (a) and corresponding complex impedance diagram (b). $R_{\mathrm{b}}$, bulk electrolyte resistance; $C_{\mathrm{g}}$, geometical capacitance; $R_{\mathrm{e}}$, electrolyte/ electrode interfacial resistance; $C_{\mathrm{e}}$, electrolyte/electrode interfacial capacitance. 
ance diagrams is expressed by Figure 1(b). At low frequencies $C_{\mathrm{g}}$ is considered to be open, and thus, the equivalent circuit can be symbolized by $R_{\mathrm{b}}$ in series with the parallel combination of $R_{\mathrm{e}}$ and $C_{\mathrm{e}}$. The impedance $(Z)$ is represented by:

$$
Z=R_{\mathrm{b}}+\frac{R_{\mathrm{e}}}{1+i \omega R_{\mathrm{e}} C_{\mathrm{e}}}
$$

The profile of the complex impedance diagram, so called Cole-Cole plots, based on eq 1 is expressed by arc 1, as shown in Figure 1(b). In the figure, the horizontal axis is a real part of $Z$, defined as resistance $\left(Z^{\prime}\right)$, and the vertical axis is an imaginary part of $Z$, defined as reactance $\left(Z^{\prime \prime}\right)$. The $Z^{\prime}$ values at low and high frequency ends of the arc 1 coincide with $R_{\mathrm{b}}+R_{\mathrm{e}}$ and $R_{\mathrm{b}}$, respectively. $f_{1}$ is the characteristic frequency of the parallel combination of $R_{\mathrm{e}}$ and $C_{\mathrm{e}}$, and is represented by:

$$
f_{1}=1 / 2 \pi R_{\mathrm{e}} C_{\mathrm{e}}
$$

At the higher frequencies the equivalent circuit is symbolized by the parallel combination of $R_{\mathrm{b}}$ and $C_{\mathrm{g}}$, its $Z$ is expressed by:

$$
Z=\frac{R_{\mathrm{e}}}{1+i \omega R_{\mathrm{e}} C_{\mathrm{g}}}
$$

The locus of eq 3 corresponds to $\operatorname{arc} 2$, as shown in Figure 1(b). $f_{2}$ is related to $R_{\mathrm{b}}$ and $C_{\mathrm{g}}$, as follows:

$$
f_{2}=1 / 2 \pi R_{\mathrm{b}} C_{\mathrm{g}}
$$

Figure 2 shows the complex impedance diagrams of the PPO complexes in contact with lithium electrodes at $70^{\circ} \mathrm{C}$. Since two arcs corresponding to the arcs 1 and 2 were observed in each complex impedance diagram, $R_{\mathrm{b}}$, $R_{\mathrm{b}}, f_{1}$, and $f_{2}$ could be estimated. Substituting these values to eq 2 and 4 , we could calculate the values of $C_{\mathrm{g}}$ and $C_{\mathrm{e}}$. Thus, all the values of the components in the equivalent circuit were obtained, as shown in Table I. $C_{\mathrm{g}}$ was in the order of $10^{-11} \mathrm{~F}$ in each PPO complex. The values corresponded to the relative dielectric constant $\left(\varepsilon_{\mathrm{r}}\right)$ of $13-14$. The $\varepsilon_{\mathrm{r}}$ values nearly
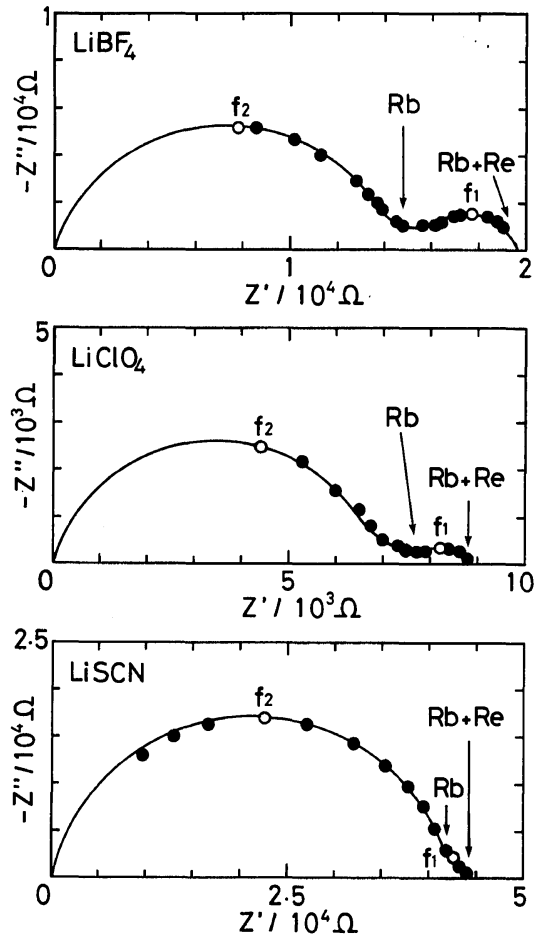

Figure 2. Complex impedance diagrams of PPO complexes ([Salt $] /[\mathrm{PO}$ unit $]=0.05$ ) in contact with lithium electrodes at $70^{\circ} \mathrm{C}$. Sample thickness: PPO- $\mathrm{LiBF}_{4}$, $0.84 \mathrm{~mm}$; PPO- $\mathrm{LiClO}_{4}, \quad 0.39 \mathrm{~mm}$; PPO-LiSCN, $0.88 \mathrm{~mm}$.

coincided with the findings by Wetton et al. that the magnitude of $\varepsilon_{\mathrm{r}}$ in the PPO $-\mathrm{ZnCl}_{2}$ complex reached of the order of $10^{1}$ at 10 $40^{\circ} \mathrm{C}^{13} R_{\mathrm{e}}$ was considerably smaller than $R_{\mathrm{b}}$, whereas $R_{\mathrm{e}}$ became very large in the cell with platinum electrodes. Thus, it is obvious that lithium electrodes operate as ion-reversible electrodes to the PPO complexes and that $R_{\mathrm{e}}$ corresponds to the interfacial charge transfer resistance. $C_{\mathrm{e}}$ which reached $10^{-7}-10^{-8} \mathrm{~F}$ corresponds to double layer capacitance resulting from the polarization of ionic carriers at the interface.

In Figure 3 are shown the complex impedance diagrams for the PPO- $\mathrm{LiBF}_{4}$ complex at 90,80 and $60^{\circ} \mathrm{C}$. Taking the results at $70^{\circ} \mathrm{C}$ in Figure 2 into consideration, it is seen that the measurable range in the complex impedance 
Table I. Values of components in equivalent circuit at $70^{\circ} \mathrm{C}$

\begin{tabular}{rllllll}
\hline Salt & $R_{\mathrm{b}} / \Omega$ & $f_{2} / \mathrm{Hz}$ & $C_{\mathrm{g}} / \mathrm{F}$ & $R_{\mathrm{e}} / \Omega$ & $f_{1} / \mathrm{Hz}$ & $C_{\mathrm{e}} / \mathrm{F}$ \\
\hline $\mathrm{LiBF}_{4}$ & $1.48 \times 10^{4}$ & $5.5 \times 10^{5}$ & $2.0 \times 10^{-11}$ & $4.7 \times 10^{3}$ & $6.0 \times 10$ & $5.6 \times 10^{-7}$ \\
$\mathrm{LiClO}_{4}$ & $7.60 \times 10^{3}$ & $5.5 \times 10^{5}$ & $3.8 \times 10^{-11}$ & $1.2 \times 10^{3}$ & $2.5 \times 10^{2}$ & $5.3 \times 10^{-7}$ \\
$\mathrm{LiSCN}$ & $4.20 \times 10^{4}$ & $2.0 \times 10^{5}$ & $1.9 \times 10^{-11}$ & $2.7 \times 10^{3}$ & $1.5 \times 10^{3}$ & $3.9 \times 10^{-8}$ \\
\hline
\end{tabular}
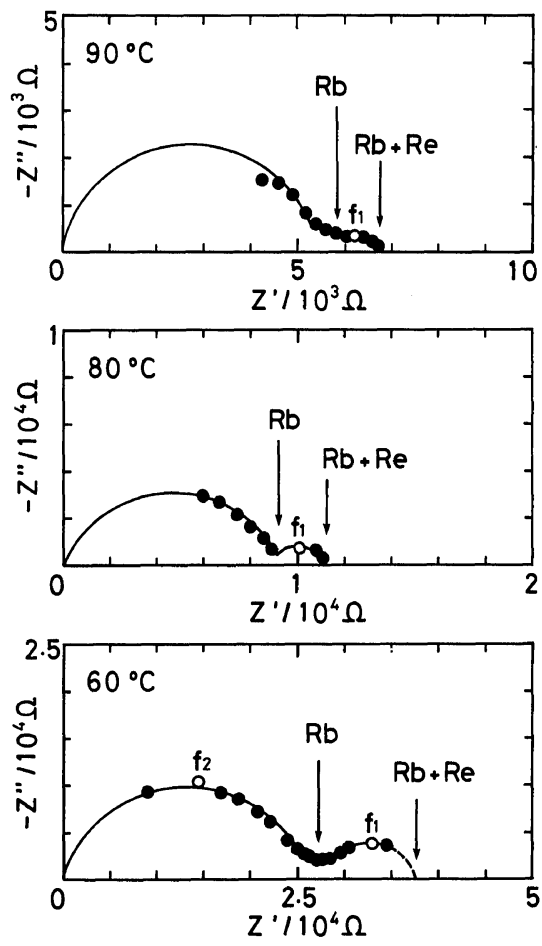

Figure 3. Complex impedance diagrams for PPO$\mathrm{LiBF}_{4}$ complex ([Salt]/[PO unit $]=0.05$ ) with the thickness of $0.84 \mathrm{~mm}$ in contact with lithium electrodes at 90 , 80 , and $60^{\circ} \mathrm{C}$.

diagrams varied with the temperature change. At $90^{\circ} \mathrm{C}$ the impedance plots cited mainly on the arc 1 , whereas at $60^{\circ} \mathrm{C} R_{\mathrm{b}}$ and $R_{\mathrm{e}}$ increased and the measurable plots were mainly concerned with the arc 2. $f_{1}$ and $f_{2}$ became low with decreasing temperature.

\section{Temperature Dependence of Ionic Conductivity}

Figure 4 shows the relation between the logarithm of the ionic conductivity $(\sigma)$ calculated from $R_{\mathrm{b}}$ and the reciprocal of absolute temperature $(1 / T)$. The temperature depen-

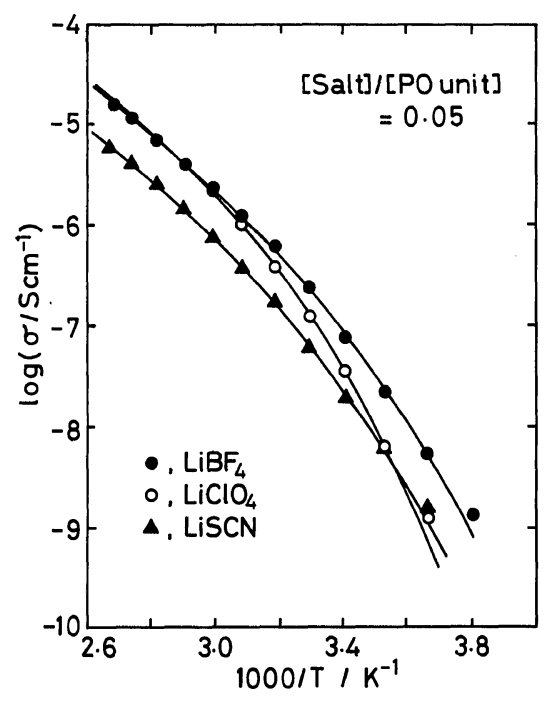

Figure 4. Relation between logarithm of ionic conductivity and reciprocal of absolute temperature.

dence did not obey the Arrhenius theory with a temperature-independent activation energy, but showed a marked deviation from a single Arrhenius behavior. The PPO complexes were transparent, amorphous, and elastic materials, and their glass transition temperatures $\left(T_{\mathrm{g}}\right)$ were lower than the measuring temperature range. It was expected that the transport of ionic carriers was related to segmental motion of the amorphous main chain. Thus, the temperature dependence of $\sigma$ was expressed by the WLF-type equation: ${ }^{14}$

$$
\log \frac{\sigma(T)}{\sigma\left(T_{\mathrm{g}}\right)}=\frac{C_{1}\left(T-T_{\mathrm{g}}\right)}{C_{2}+\left(T-T_{\mathrm{g}}\right)}
$$

By using $T_{\mathrm{g}}$ 's determined from DSC measurements, the data sets of $C_{1}, C_{2}$, and $\sigma\left(T_{\mathrm{g}}\right)$ were so calculated as to best linearize the correlation between $1 /\left(T-T_{\mathrm{g}}\right)$ and $1 / \log [\sigma(T) /$ 
Table II. WLF parameters for PPO complexes

\begin{tabular}{|c|c|c|c|c|c|}
\hline \multirow{2}{*}{ Salt } & $T_{\mathrm{g}}$ & & \multirow{2}{*}{$C_{1}$} & \multirow{2}{*}{$\frac{C_{2}}{{ }^{\circ} \mathrm{C}}$} & \multirow{2}{*}{$\frac{\sigma\left(T_{\mathrm{g}}\right)}{\mathrm{Scm}^{-1}}$} \\
\hline & ${ }^{\circ} \mathrm{C}$ & & & & \\
\hline \multirow{3}{*}{$\mathrm{LiBF}_{4}$} & Onset & -40 & 12.0 & 53.7 & $3.9 \times 10^{-14}$ \\
\hline & Center & -30 & 10.1 & 64.1 & $3.1 \times 10^{-12}$ \\
\hline & End & -21 & 8.8 & 75.0 & $6.6 \times 10^{-11}$ \\
\hline \multirow{3}{*}{$\mathrm{LiClO}_{4}$} & Onset & -34 & 15.0 & 33.4 & $2.2 \times 10^{-17}$ \\
\hline & Center & -24 & 11.5 & 43.5 & $5.6 \times 10^{-14}$ \\
\hline & End & -14 & 9.4 & 53.4 & $8.0 \times 10^{-12}$ \\
\hline \multirow{3}{*}{ LiSCN } & Onset & -47 & 14.6 & 47.0 & $5.8 \times 10^{-17}$ \\
\hline & Center & -33 & 11.3 & 60.9 & $1.1 \times 10^{-13}$ \\
\hline & End & -19 & 9.2 & 76.6 & $1.6 \times 10^{-11}$ \\
\hline
\end{tabular}

$\sigma\left(T_{\mathrm{g}}\right)$ ]. Table II shows the WLF parameters obtained. Onset, center, and end temperatures of the heat capacity change in the DSC charts, which was experienced in glass transition zone, were used as $T_{\mathrm{g}}$ for each calculation. Some deviation in the WLF parameters was noticed depending on the used $T_{\mathrm{g}}$, however, their values were considered comparable to the universal values of $C_{1}=17.4$ and $C_{2}=51.6$ for the temperature dependence of the relaxation times of amorphous main chain. This implied that the temperature dependence of the ionic mobility which correlated to the segmental mobility of the PPO main chain dominated the temperature dependence of $\sigma$.

\section{Temperature Dependence of Interfacial Charge}

Transfer Resistance

Since $R_{\mathrm{e}}$ is known to be proportional to the area in contact with electrodes, ${ }^{15} R_{\mathrm{e}}$ per unit area is used as normalized $R_{\mathrm{e}}$ and is expressed by $\rho_{\mathrm{e}}$. Figure 5 shows the relation between $\log \rho_{\mathrm{e}}$ and $1 / T$. It was found that the temperature dependence of $\rho_{\mathrm{e}}$ obeyed the Arrhenius equation:

$$
\rho_{\mathrm{e}}=\rho_{\mathrm{e}_{0}} \exp \left(E_{\mathrm{a}} / k T\right)
$$

where $\rho_{\mathrm{e}_{0}}$ is a constant, and $k$ is the Boltzmann constant. $\rho_{\mathrm{e}_{0}}$ was $1.4 \times 10^{-12}, 3.5 \times 10^{-15}$, and $9.4 \times 10^{-6} \Omega \mathrm{cm}^{-2}$ for PPO-LiBF 4 , PPO-

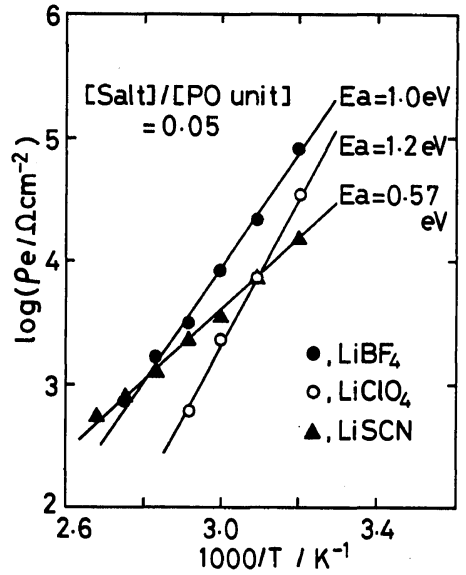

Figure 5. Relation between logarithm of normarized interfacial charge transfer resistance in contact with lithium electrodes and reciprocal of absolute temperature.

$\mathrm{LiClO}_{4}$, and PPO-LiSCN complexes, respectively. The activation energy $\left(E_{\mathrm{a}}\right)$ ranged from 0.57 to $1.2 \mathrm{eV}$, depending on the kinds of the incorporated salts. Since the charge transfer resistance was based on the electrode reactions, $\mathrm{Li} \rightleftarrows \mathrm{Li}^{+}+\mathrm{e}$, the $E_{\mathrm{a}}$ values seemed to correspond to the activation energy for the electrode reactions.

\section{CONCLUSION}

It was concluded that the temperature dependences of the ionic conductivity and the interfacial charge transfer resistance, corresponding to the electrode reactions $\left(\mathrm{Li} \rightleftarrows \mathrm{Li}^{+}+\mathrm{e}\right.$ ), for the PPO-lithium salt complexes in contact with lithium electrodes obeyed the WLF-type equation and the Arrhenius equation, respectively. The WLF parameters obtained were $C_{1} \simeq 9-15$ and $C_{2} \simeq 35-75$, and the $E_{\mathrm{a}}$ values were $0.57-1.2$ $\mathrm{eV}$, depending on the kinds of the incorporated salts.

\section{REFERENCES}

1. P. V. Wright, Br. Polym. J., 7, 319 (1975).

2. M. B. Armand, J. M. Chabagno, and M. J. Duclot, 
"Fast Ion Transport in Solids," P. Vashishta, J. M. Mundy, and G. K. Shenoy, Eds., North Holland, New York, N.Y., 1979, p 131.

3. B. L. Papke, M. A. Ratner, and D. F. Shriver, J. Phys. Chem. Solid, 42, 493 (1981).

4. B. L. Papke, M. A. Ratner, and D. F. Shriver, J. Electrochem. Soc., 129, 1694 (1982).

5. J. M. Parker, P. V. Wright, and C. C. Lee, Polymer, 22, 1305 (1981).

6. C. C. Lee and P. V. Wright, Polymer, 23, 681 (1982).

7. D. R. Payne and P. V. Wright, Polymer, 23, 690 (1982).

8. D. Dupon, B. L. Papke, M. A. Ratner, D. H. Whitmore, and D. F. Shriver, J. Am. Chem. Soc., 104, 6247 (1982).

9. M. Watanabe, J. Ikeda, and I. Shinohara, Polym. J.,
15, 65 (1983).

10. M. Watanabe, J. Ikeda, and I. Shinohara, Polym. J., 15, 175 (1983).

11. K. Nagaoka, F. Endo, H. Naruse, E. Tsuchida, I. Shinohara, and M. Watanabe, Polym. Prepr., Jpn., 32, 2641 (1983).

12. P. R. Sorensen and T. Jacobsen, Electrochim. Acta, 27, 1671 (1982).

13. R. E. Wetton and D. B. James, Polym. Prepr., Am. Chem. Soc., Div. Polym. Chem., 19, 353 (1978).

14. M. L. Williams, R. F. Landel, and J. D. Ferry, J. Am. Chem. Soc., 77, 3701 (1955).

15. P. H. Bottelberphs, "Solid Electrolytes," P. Hagenmuller and W. V. Gool Eds., Academic, New York, N.Y., 1978, p 145. 